\title{
Back Issues of
}

\section{Pergamon International Research Journals}

Back issues of this and other essential Pergamon journals are available in hard copy or microform. New subscribers to a journal may purchase back issues of that publication in hard copy and microform editions at $25 \%$ discount, on the standard price. Stocks of back issues are maintained at all of Pergamon's numerous worldwide offices, and orders may be placed with confidence at the location most convenient to you. Should any issue of a volume be temporarily out of stock at the time of ordering, a photoduplicated copy will be supplied at no extra charge to complete your order.

\section{Save up to 33\% by Purchasing Complete Sets}

Customers wishing to purchase complete sets can do so at a saving of $25 \%$ to $33 \%$ less than the individual volume price.

\section{Hard Copies}

Complete sets of back volumes of journals are available in hard copy and microform at discounts ranging from $25 \%$ to $33 \%$.

\section{The Microform Alternative}

A very competitive price alternative to the hard copy is microform which represents a substantial saving of a further $50 \%$ on microfilm and $20 \%$ on microfiche

\section{Microform at 50\%: Special Trade-in Price for Back Issues}

A hard copy back issue volume of any Pergamon Press journal, or the immediately preceding volume in hard copy, may be traded-in against the same volume or volumes in microform. The trade-in allowance is $50 \%$ off the listed price of the microfilm or microfiche, and applies to both separate reels and complete back issue sets.

\section{Back Issues Price List}

Full details of the rates for back issues of all Pergamon journals cán be found in our Back Issues Price List. Please contact your nearest Pergamon office for a copy. 


\section{This Journal is also Available in MICROFORM}

Combined hard-copy and microform subscription:

(a) microfiche by airmail immediately after the publication of the hard-copy edition;

(b) microfilm immediately after publication of the last issue of the subscription year.

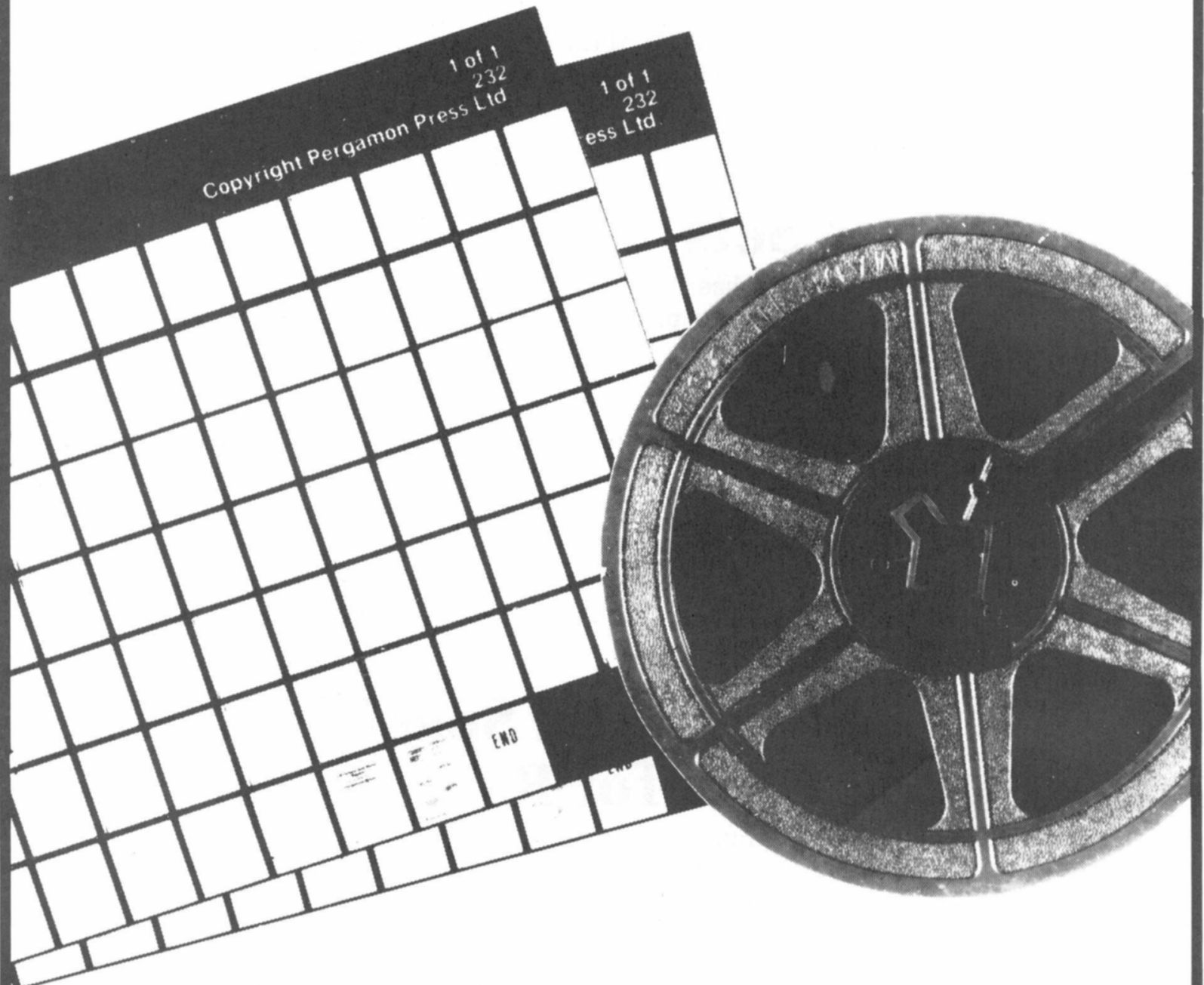

The purchase of a combined hard-copy and microform subscription to any Pergamon Press journal entitles the purchaser to unlimited reproduction of articles in that journal, providing that copies are not for resale.

Back issues are available in microfiche, microfilm, or hard-copy edition.

For further information, write to

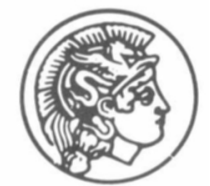

\section{PERGAMON PRESS}

at your most convenient address:

Headington Hill Hall, Oxford OX3 0BW, England

Fairview Park, Elmsford, New York 10523, USA 


\title{
Insect Science and its Application
}

\author{
The International Journal of Tropical Insect Science
}

\begin{abstract}
Aims and Scope
Insect Science and its Application deals comprehensively with all aspects of scientific research targeted on tropical insects (and related arthropods), and the application of new discoveries to such diverse fields as pest and vector management and the use of insects for human welfare.

A distinctive feature of the journal is its multi- and interdisciplinary nature, which transcends the traditional boundaries of entomology.

Its second feature is its concentration on the recording and reviewing of the progress of insect science in the tropical and subtropical regions of the world. Thus, without excluding any area of the wide field encompassed by insect science, the journal will accept manuscripts in environmental physiology, the regulation of development and reproduction, population modelling, chemical ecology, natural products chemistry, plant resistance, host/insect relations, behaviour of tropical pest species, epidemiology of tropical diseases, vector biology, pest and vector management research, entomo-meteorology, insects in relation to farming systems, forest entomology, insect pathology, social insects and arthropods, and the use of insects. It is the intention of the Editors to have manuscripts published rapidly, consistent with the needs of quality control.

In addition to articles of original research, the journal also publishes book reviews, announcements and reports of meetings and mini-reviews. Each regular issue of the journal contains a short review article on a critical or rapidly developing area of tropical insect science; normally the Editors will have invited an author to contribute such a mini-review.
\end{abstract}

\section{Information for Contributors}

1. All papers for publication in Insect Science and Its Application should be submitted directly to the Editor-in-Chief, Professor Thomas R. Odhiambo, Scientific Editorial Services, P.O. Box 59900, Nairobi, Kenya. Papers should be mailed in a strong, preferably linen, envelope, as they may otherwise arrive in a damaged condition.

2. Papers should be in English or French and be original contributions in the field of tropical insect science. Each paper should have a summary in the form of an abstract in both English and French.

3. Submission of a paper implies that it has not been published previously, that it is not under consideration for publication elsewhere, and that if accepted for Insect Science and Its Application the authors will transfer copyright to Pergamon Press as is customary. Articles and illustrations become the property of the journal. There is no page charge for papers accepted for publication.

4. Manuscripts and illustrations must be submitted in triplicate to ensure efficient refereeing, and the author should retain a copy. In the case of multiple authorship the authors should indicate who is to receive correspondence.

5. Manuscripts must be typewritten with double spacing (including the reference list), and with wide margins on one side of the paper only. Authors are requested to keep their communications as concise as possible. Footnotes should be avoided, and italics should not be used for emphasis. A running head of not more than 30 letters should be supplied.

6. Twenty-five free reprints will be supplied to the first-named author of each paper published in the journal. Detailed Instructions to Authors for the preparation of manuscripts are available from the Editor-in-Chief or the Publishing Office. 


\section{Insect Science \\ and its Application}

The International Journal of Tropical Insect Science

VOLUME 5 NUMBER 4

\section{CONTENTS}

John B. KadDu and Mutuku J. Mutinga

D. K. Punyua, R. M. Newson and

M. J. Mutinga

D. K. PUNYUA

M. F. IVBIJARo

Aliyageen M. Alghali

G. W. OLOo

C. F. Curtis, A. Keto, B. D. Rami and I. Iosson

D. M. SabWA, M. O. Odindo and

W. A. OTIENO

IFEDIORAMMA E. NWANA

C. Inayatullah

C. M. WARUI

B. U. Singh and B. S. Rana

L. H. Otieno, R. M. W. Vundla and A. MONGI

JACOB G. YARRO

JOSEPH B. ACKONOR

Syed Khasimuddin and Morton C. Lubega

This journal is now listed in

Current Awareness in Biological Sciences. Send to your nearest Pergamon office for a free specimen copy.
237 Obituary

239 Leishmania in Kenyan phlebotomine sandflies-II. Natural infection in the malpighian tubules of Sergentomyia garnhami and Sergentomyia antennatus

245 Diurnal and seasonal activity of unfed adult Rhipicephalus appendiculatus (Acarina: Ixodidae) in relation to some intrinsic and extrinsic factors-II. Factors affecting vertical distribution of ticks in the habitat

247 Development periods of Rhipicephalus appendiculatus Neumann (Acarina: Ixodidae) under field conditions

251 Toxic effects of groundnut oil on the rice weevil Sitophilus oryzae (L.)

253 Studies on the biology, damage and crop loss assessment of the sorghum midge, Contarinia sorghicola Coq. (Diptera: Cecidomyiidae)

259 Some observations on the trail-laying behaviour of Macrotermes michaelseni (Sjöst) (Termitidae)

263 Assessment of the impact of chlorpyrifos resistance in Culex quinquefasciatus on a control scheme

269 Seasonal incidence of Amblyospora sp. (Thelohaniidae: Microsporidia) in Culex sitiens larvae at the Kenya coast

273 The dispersal of the variegated grasshopper, Zonocerus variegatus (Linnaeus) (Orthoptera, Acridoidea, Pyrgomorphidae), in open fields and cultivated farms

279 Sugar-cane aleurodids, Aleurolobus barodensis (Maskell) and Neomaskellia andropogonis Corbett (Hom.: Aleyrodidae), and their natural enemies in Pakistan

283 Bruchid infestation of cowpea varieties in the field

287 Influence of varietal resistance on oviposition and larval development of stalk-borer Chilo partellus Swin., and its relationship to field resistance in sorghum

297 Observations on Glossina morsitans morsitans maintained on rabbits immunized with crude tsetse midgut proteases

303 Life and fertility tables for Spodoptera exempta (Wlk.) (Lepidoptera, Noctuidae)

307 The activity pattern of the ant Cataulacus guineensis F. Smith (Hymenoptera:Formicidae) in a Ghanaian cocoa farm

325 Quantitative bioassays for sex pheromone analysis in Spodoptera exempta (Wlk.) (Lepidoptera, Noctuidae), and laboratory evidence of cross-attraction among three species 